\title{
UTILIZAÇÃO DE PLACA DE TITÂNIO SEMITUBULAR COM GARRAS PARA ESTABILIZAÇÃO DAS FRATURAS DE RÁDIO E ULNA DE CÃES MINIATURAS
}

\author{
FABRício Bernardo de Jesus BRASIL ${ }^{1}$ \\ 1. Professor titular do Centro Regional Universitário de Espírito Santo do Pinhal, UNIPINHAL, e Faculdade Dr. Francisco Maeda, FAFRAM.
}

\section{RESUMO}

O terço distal do rádio e ulna é o local de maior incidência dos processos traumáticos dos membros torácicos em cães. Particularmente em raças miniaturas, as fraturas do terço distal do rádio e da ulna estão frequentemente associadas a complicações, tais como a falta de união óssea ou união retardada no foco de fratura. Levando em consideração a alta incidência dessas complicações no tratamento de fraturas do rádio e ulna de animais miniaturas, iniciou-se esta pesquisa, com o objetivo de superar tais problemas, o que levou ao desenvolvimento de uma placa com três garras em cada face lateral, em duas dimensões. As referidas placas foram projetadas e fornecidas por empresas produtoras de implantes ortopédicos. Conceberam-se as dimensões do protótipo com base em peça anatômica do rádio e ulna de cão miniatura. As placas foram aplicadas com auxílio de alicate ortopédico de 23,0 $\mathrm{cm}$ de comprimento, em animais com peso variando de 0,5 a 2,5 $\mathrm{kg}$, placa menor (01), e em animais com peso de 2,5 a 5,0 kg, placa maior (02). Ambas apresentavam comprimento total de $40,0 \mathrm{~mm}$ e larguras diferentes $(9,0 \mathrm{~mm}$ para placa menor e $11,0 \mathrm{~mm}$ para placa maior). $\mathrm{O}$ presente trabalho teve a finalidade de avaliar o uso de placas de titânio, semitubulares, com garras, desenvolvidas especialmente para o tratamento de fraturas de rádio e ulna de cães miniaturas. Num período de quatorze meses, atendeu-se a quinze animais com fratura de rádio e ulna, os quais tiveram as placas implantadas e, posteriormente, avaliadas por meio de exame clínico e radiológico a cada trinta dias. Os animais recuperaram a função dos membros operados entre quatro e sete dias após a cirurgia. Radiograficamente, verificou-se a consolidação óssea em todos os cães, num período inferior a noventa dias. Complicações pósoperatórias ocorreram em dois casos, com rotação do fragmento ósseo distal seguido de perda da função dos parafusos distais em um paciente, e exposição da extremidade distal da placa que teve de ser retirada, em outro.

PALAVRAS-CHAVES: Cães, ortopedia, placa semitubular com garras.

\section{ABSTRACT}

\section{UTILIZATION OF SEMITUBULAR TITANIUM PLATES WITH CLAMPS FOR STABILIZING RADIAL AND ULNAR FRACTURES IN MINIATURE DOGS}

The distal third of the radius and ulna is the most prevalent site in traumatic processes of thoracic limbs in dogs. Especially in miniature breeds, fractures on the distal third of the radius and ulna are frequently associated with complications such as lack of bone union or delayed union at the fracture focus. The purpose of this paper was to assess the use of semitubular titanium plates with clamps specially developed for treating radial and ulnar fractures in miniature dog breeds. In a 14-month period, 15 animals were seen with radial and ulnar fracture, which had had a plate implant and afterwards were assessed by means of a clinical and radiological examination every 30 days. The animals recovered the function of their operated limbs between 4 and 7 days after the surgery. By $\mathrm{X}$-ray examination, bone consolidation was observed in all dogs in less than 90 days. Post-op complications occurred in two cases: rotation of the distal bone fragment after loss of function of distal screws in one dog, and in another, exposure of distal end of plate, which had to be removed. The use of the plate with clamps is an effective technique to correct this type of fracture.

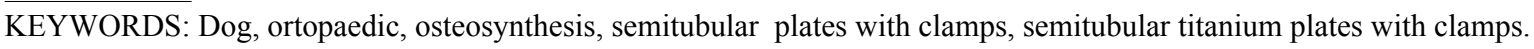




\section{INTRODUÇÃO}

As fraturas do rádio e da ulna representam de $8,5 \%$ a $18 \%$ da casuística de fraturas nos cães e gatos, constituindo-se como o terceiro tipo mais frequente em cães. Podem ser completas ou incompletas, acometer somente um dos ossos ou ambos, resultando em presença ou ausência de falha óssea. Dentre as causas mais comuns destacam-se acidentes automobilísticos, ou após traumas aparentemente mínimos, tais como salto ou queda de pequenas alturas (LAPPIN et al., 1983; ROCHAT \& PAYNE, 1993; WATERS et al., 1993; MUIR, 1997).

O terço distal dos ossos rádio e ulna é o local de maior incidência dos processos traumáticos do membro torácico, em face da presença de grande quantidade de tecido esponjoso nesta região, pequeno diâmetro do osso, alterações relacionadas na geometria e/ou densidade mineral, pouca vascularização e musculatura de suporte, frequentemente associados a problemas de falta de união ou de união retardada em raças miniaturas (WELCH, 1997; BRIANZA et al., 2006).

As alternativas de tratamento dessas fraturas estão divididas em técnicas conservativas e cirúrgicas. Para as fraturas do terço distal de rádio e ulna em raças miniaturas, a imobilização externa tem incidência elevada (75\%) de não união, má união ou instabilidade do foco de fratura, sendo indicadas, nesses casos, técnicas que minimizem tais problemas e otimizem a consolidação por meio da redução anatômica, estabilização adequada, preservação da circulação óssea e reabilitação precoce (LAPPIN et al., 1983; WATERS et al., 1993).

Levando-se em consideração a ocorrência de complicações nas fraturas radiais distais em raças pequenas, as técnicas podem variar entre o uso de pinos intramedulares, placas de fixação rígida com parafusos, placas de reconstrução, placas biodegradáveis, placas que preservam o suprimento sanguíneo periosteal, chamados de fixadores internos (PC-Fix), associados a enxerto autógeno de osso esponjoso (RUDD \& WHITEHAIR, 1992; LARSEN et al., 1999; HAAS et al., 2001; SAIKKU et al., 2005; ADAMIAK \& ALEKSIEWICZ, 2006).

Outros modelos de placas são utilizados como alternativas de osteossíntese em ossos longos, na medicina veterinária. COETZEE (1999) utilizou um modelo de placa com sistema de braçadeiras, chamada de placa clamp, como método alternativo de tratamento. Para as fraturas extremamente distais ou correções de deformidades angulares, uma miniplaca em " $\mathrm{T}$ " que permita a aplicação de dois ou mais parafusos no plano transversal distal poderá ser utilizada em cães de pequeno porte e gatos (BALFOUR et al., 2000; HAMILTON \& LANGLEY HOBBS, 2005).

Após a invenção desses implantes metálicos, muitas complicações na consolidação têm sido observadas. Elas resultam da interferência dos materiais no pobre suprimento sanguíneo do rádio e ulna distal, nas raças miniaturas, em consequência da necessidade do afastamento de tecidos moles e periósteo para aplicação desses implantes, e em particular, dos danos aos vasos sanguíneos do endósteo causados pelas brocas ou pinos acopladas a furadeiras de alta rotação para colocação de parafusos (ROCHAT \& PAYNE, 1993).

Os fixadores externos do tipo Ehmer-Kirschner ou circulares também podem ser o método de escolha para o tratamento de fraturas de rádio e ulna em cães pequenos, independente do tipo. Por serem adaptáveis de várias maneiras, eles são particularmente indicados em fraturas abertas ou instáveis e também como forma de tratamento para as complicações que ocorrem nas raças miniaturas, tais como uniões retardadas, não uniões e deformidades angulares (RUDD \& WHITEHAIR, 1992; HARARI et al., 1998; RAHAL et al., 2005).

Levando em consideração a alta incidência de complicações no tratamento de fraturas do rádio e ulna de animais miniaturas, iniciou-se pesquisa voltada para superar tais problemas, o que levou ao desenvolvimento de uma placa visando diminuir tais complicações. Objetivouse com o presente estudo foi o de avaliar clinicamente e radiograficamente a técnica do uso de placas de titânio semitubulares com garras desenvolvidas especialmente para a correção de fraturas de rádio e ulna de cães miniaturas como uma alternativa para o seu tratamento.

\section{MATERIAL E MÉTODOS}

Foram avaliados quinze cães, pesando entre 2,4 e 4,0 kg (média: $3,3 \mathrm{~kg}$ ) e idade variando de quatro meses a quatro anos (média: quinze meses), e que apresentaram fraturas simples fechadas (transversa ou oblíqua curta) no terço distal de rádio e ulna (Quadro 1). Dois cães apresentavam fraturas bilaterais, totalizando dezessete procedimentos de correção com placa com garras. 
póreo, sexo e etiologia das fraturas dos cães atendidos nos hospitais veterinários da FCAV UNESP-Jaboticabal e Unipinhal, tratados com placa com garras

\begin{tabular}{cccccc}
\hline Cães & Raça & Idade & Peso $(\mathrm{kg})$ & Sexo & Etiologia \\
\hline 1 & Poodle & $6 \mathrm{~m}$ & 3,2 & $\mathrm{~F}$ & Queda \\
2 & Pinscher & $1 \mathrm{a}$ & 2,5 & $\mathrm{~F}$ & Desconhecida \\
3 & Poodle & $2 \mathrm{a}$ & 2,3 & $\mathrm{~F}$ & Mordida de outro cão \\
4 & Pincher & $9 \mathrm{~m}$ & 4,0 & $\mathrm{~F}$ & Queda \\
5 & Pinscher & $1^{\mathrm{a}}$ & 3,1 & $\mathrm{M}$ & Queda \\
6 & Pinscher & $9 \mathrm{~m}$ & 2,8 & $\mathrm{~F}$ & Chute \\
7 & Pinscher & $4 \mathrm{a}$ & 3,7 & $\mathrm{~F}$ & Queda \\
8 & Poodle & $1 \mathrm{a}$ & 2,1 & $\mathrm{~F}$ & Desconhecida \\
9 & Poodle & $5 \mathrm{~m}$ & 4,3 & $\mathrm{~F}$ & Queda \\
10 & Pinscher & $2 \mathrm{a}$ & 2,9 & $\mathrm{M}$ & Atropelamento \\
11 & Pinscher & $1 \mathrm{a}$ & 2,4 & $\mathrm{M}$ & Queda \\
12 & Poodle & $2 \mathrm{a}$ & 4,3 & $\mathrm{M}$ & Queda \\
13 & Poodle & $8 \mathrm{~m}$ & 3,4 & $\mathrm{~F}$ & Mordida de outro cão \\
14 & Poodle & $1 \mathrm{a}$ & 4,8 & $\mathrm{M}$ & Queda \\
15 & Poodle & $5 \mathrm{~m}$ & 3,6 & $\mathrm{~F}$ & Atropelamento \\
\hline
\end{tabular}

Abreviaturas: $\mathrm{m}=$ meses, $\mathrm{a}=$ anos, $\mathrm{F}=$ fêmea, $\mathrm{M}=$ macho

$\mathrm{Na}$ avaliação inicial, os animais apresentavam aumento de volume do membro traumatizado, dor, mobilidade anormal dos ossos rádio e ulna fraturados, crepitação óssea e impotência funcional do membro torácico traumatizado. Todos os animais apresentaram-se com fraturas agudas ( $<$ sete dias da ocorrência do trauma), sem terem recebido tratamento. Dois dos quinze cães atendidos apresentaram fraturas bilaterais e não houve a ocorrência de fraturas expostas. Dois cães tiveram fraturas bilaterais, seis tiveram fraturas no rádio e ulna esquerdos e sete tiveram no rádio e ulna direitos. Oito cães tiveram fraturas no terço médio do rádio e ulna e nove no terço distal. Observando a linha de fratura, ocorreram oito fraturas transversas e nove oblíquas curtas. Os animais foram examinados em pós-operatório de dez dias, observando-se seus estados gerais e aspectos clínicos das feridas cirúrgicas e momento de apoio dos membros operados, em avaliações mensais.

Empregaram-se placas semitubulares de titânio (Ti-6Al-4V) com garras, jateadas com microesferas de vidro, em dois tamanhos, com cinco orifícios, dois distais e três proximais, para parafusos corticais de 2,0 $\mathrm{mm}$, desenvolvidas especialmente para o tratamento de fraturas de rádio e ulna de cães miniaturas. Os implantes metálicos foram projetados e fornecidos por empresas produtoras de implantes ortopédicos (Figura 1). A placa menor (1) foi aplicada em animais com peso variando de 0,5 a $2,5 \mathrm{~kg}$ e a placa maior (2) em animais com peso de 2,5 a 5,0 kg.

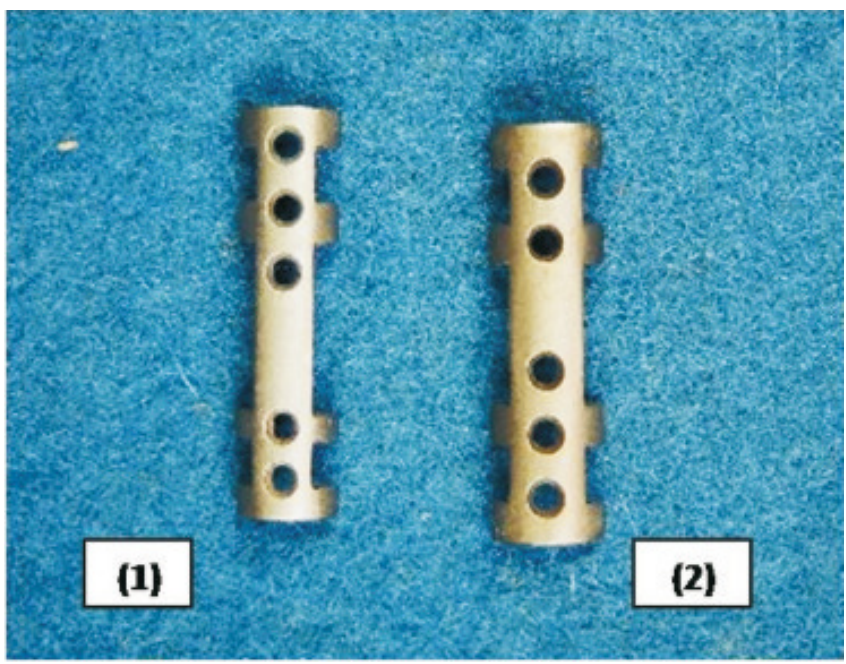

FIGURA 1. Imagem fotográfica da superfície superior das placas de titânio semitubulares com garras, utilizadas no presente estudo. Observar larguras diferentes. 
Os animais foram pré-medicados com cefalexina na dose de $20 \mathrm{mg} / \mathrm{kg}$ antes do ato cirúrgico e submetidos ao protocolo anestésico mais adequado a cada paciente.

Efetuaram-se as osteosínteses dos ossos rádio e ulna. Para tanto, após tricotomia e preparo rotineiro de campo operatório, foi realizada incisão cutânea na face crânio medial da região distal dos ossos citados. A seguir, efetuaram-se a divulsão dos tecidos subjacentes, a localização, o isolamento e afastamento dos tendões dos músculos extensor carpoulnar e extensor digital lateral e dos músculos extensor longo do polegar e da cabeça ulnar do músculo flexor digital profundo. Iniciaram-se, então, os procedimentos de escolha do implante (placa 01 ou placa 02), a redução e alinhamento dos fragmentos da fratura e a abertura das garras com auxílio de alicate ortopédico de 23,0 cm de comprimento, com aplicação da placa no rádio, confecção dos furos no osso com broca de $1,0 \mathrm{~mm}$, mensuração deste com medidor de cortical, aperto das garras com referido alicate, fixação dos parafusos com chave sextavada, compreendendo a fixação final da placa de tamanho adequado ao osso (Figura 2).

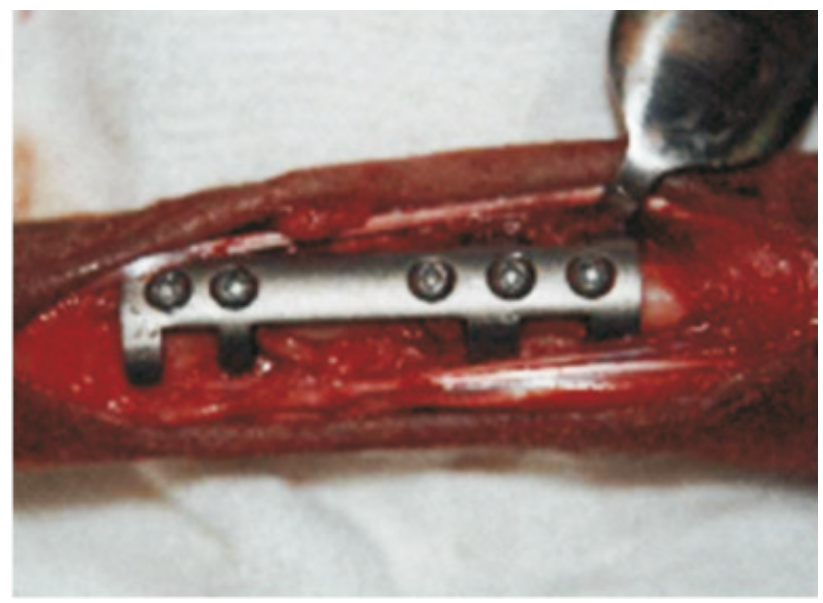

FIGURA 2. Imagem fotográfica do aspecto da fixação definitiva da placa com garras na diáfise radial, em fratura no terço distal.

Após os procedimentos cirúrgicos os animais foram examinados em pós-operatório de dez dias, observando-se: estado geral, aspecto clínico da ferida cirúrgica e momento de apoio dos membros operados. Receberam curativos diários, antibioticoterapia à base de cefalexina ${ }^{1} 1(20 \mathrm{mg} / \mathrm{kg})$, durante dez dias, e tramadol$^{2} 2(2 \mathrm{mg} / \mathrm{kg}$, cada oito horas), durante seis dias. Os momentos de apoio dos membros operados foram averiguados por meio de consultas semanais.

As análises radiográficas foram efetuadas nos devidos tempos de observação (trinta, sessenta, noventa dias de pós-operatório), para avaliação da velocidade de formação do calo ósseo. Todos os rádios e ulnas foram radiografados na projeção mediolateral e craniocaudal. Referente à consolidação, seis consolidaram em trinta dias, também seis em sessenta dias e quatro em noventa dias. As radiografias do pré-operatório nas projeções lateromedial e craniocaudal revelaram o tipo da linha de fratura.

\section{RESULTADOS}

As placas com garras foram usadas para estabilizar dezessete fraturas agudas de antebraço, sem utilização de enxerto autógeno de osso esponjoso e imobilização externa no pós-operatório. A análise clínica constou da avaliação dos seguintes parâmetros: alinhamento ósseo, tempo de união radiográfica, complicações, remoção da placa e função do membro operado (Quadro 2).

O tempo de união nos aspectos radiográfico seriados obtidos foram semelhantes para todos os animais no pós-operatório imediato. No entanto, houve discreta mudança no padrão radiográfico nas avaliações posteriores. Em relação aos lados do membro traumatizado (Figura $3 \mathrm{Ae} \mathrm{B}$ ), o estudo radiográfico do pós-operatório imediato em todos os animais mostrou que as placas estavam bem posicionadas e as linhas de fratura estavam completamente coaptadas (Figura $3 \mathrm{C}$ ). Aos trinta dias, as placas encontravam-se bem posicionados, com manutenção do eixo ósseo, ausência de reação periosteal exuberante na cortical oposta à placa e união da linha de fratura do rádio e da ulna. Aos sessenta dias, os implantes permaneceram bem posicionados, com ausência de reação periosteal e endosteal, ausência de calo ósseo e diminuição da visualização da linha de fratura em consequência do início da união das corticais. Aos noventa dias, a linha de fratura mostrava-se imperceptível e observou-se união direta das corticais opostas à placa sem presença de calo exuberante.

\footnotetext{
${ }_{1}^{1}$ Cefalexina $250 \mathrm{mg}$ - Genérico.

2 Tramadol gotas - Genérico.
} 
QUADRO 2. Parâmetros analisados na avaliação clínica da reparação das fraturas de rádio e ulna mediante aplicação das placas de titânio semitubulares com garras

\begin{tabular}{|c|c|c|c|c|c|c|}
\hline $\begin{array}{l}\text { Caso } \\
\mathrm{N} .\end{array}$ & Linha da fratura & $\begin{array}{l}\text { Alinhamento } \\
\text { ósseo }\end{array}$ & $\begin{array}{l}\text { Tempo de união } \\
\text { radiográfica }\end{array}$ & Complicações & $\begin{array}{l}\text { Remoção } \\
\text { da placa }\end{array}$ & $\begin{array}{l}\text { Função do } \\
\text { membro }\end{array}$ \\
\hline 1 & $\begin{array}{l}\text { Fratura oblíqua curta } \\
\text { dir. fratura transversa } \\
\text { esq. }\end{array}$ & Excelente & Trinta dias & Não & Não & Normal \\
\hline 2 & Fratura oblíqua curta & Excelente & Noventa dias & $\begin{array}{l}\text { Rotação do fragmento } \\
\text { distal, perda da função dos } \\
\text { parafusos distais }\end{array}$ & Não & Normal \\
\hline 3 & Fratura oblíqua curta & Excelente & Sessenta dias & Não & Não & Normal \\
\hline 4 & Fratura transversa & Excelente & Trinta dias & $\begin{array}{l}\text { Exposição da porção distal } \\
\text { da placa }\end{array}$ & Sim & Normal \\
\hline 5 & Fratura oblíqua curta & Excelente & Sessenta dias & Não & Não & Normal \\
\hline 6 & Fratura transversa & Excelente & Trinta dias & Não & Não & Normal \\
\hline 7 & Fratura oblíqua curta & Excelente & Noventa dias & Não & Não & Normal \\
\hline 8 & Fratura oblíqua curta & Excelente & Sessenta dias & Não & Não & Normal \\
\hline 9 & Fratura transversa & Excelente & Trinta dias & Não & Não & Normal \\
\hline 10 & Fratura transversa & Excelente & Sessenta dias & Não & Não & Normal \\
\hline 11 & Fratura transversa & Excelente & Sessenta dias & Não & Não & Normal \\
\hline 12 & $\begin{array}{l}\text { Fratura oblíqua curta } \\
\text { bilateral }\end{array}$ & Excelente & Noventa dias & Não & Não & Normal \\
\hline 13 & Fratura transversa & Excelente & Trinta dias & Não & Não & Normal \\
\hline 14 & Fratura oblíqua curta & Excelente & Sessenta dias & Não & Não & Normal \\
\hline 15 & Fratura transversa & Excelente & Trinta dias & Não & Não & Normal \\
\hline
\end{tabular}

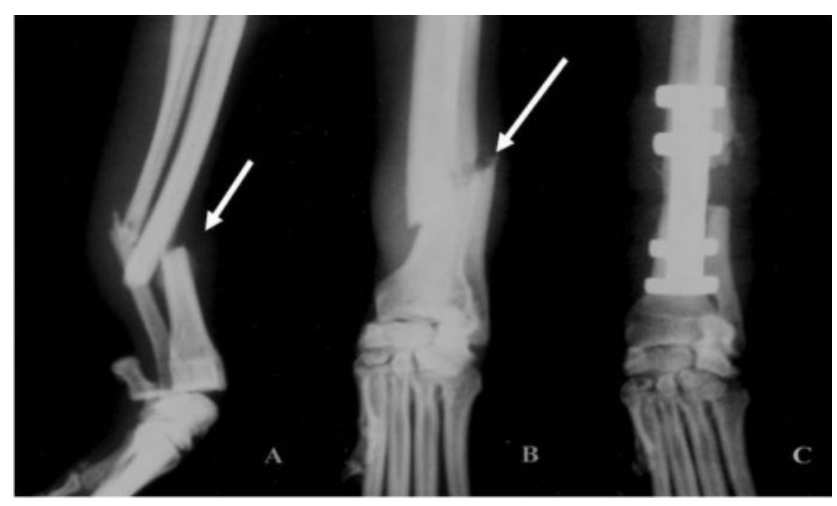

FIGURA 3. Imagens radiográficas de fratura distal de rádio e ulna. Observar sobreposição óssea dos fragmentos fraturados-projeção: mediolateral (seta) (A); linha de fratura oblíqua curta no terço distal de rádio e ulna - projeção craniocaudal (seta) (B); correção cirúrgica da fratura utilizando placa de titânio semitubular com garras, com preservação do eixo ósseo e ostectonia ulnar (seta) (C).

\section{DISCUSSÃO}

O manejo das fraturas do terço distal de rádio e ulna após trauma aparentemente mínimo permanece um problema em raças miniaturas, pois o tratamento inapropriado poderá ocasionar dificuldade ou ausência de consolidação do foco de fratura (RUDD \& WHITEHAIR, 1992). O sucesso da consolidação óssea geralmente ocorre após estabilização rígida, como é o caso da aplicação de placa e parafusos combinada ao uso de enxerto autógeno de osso esponjoso, ou de proteína morfogenética óssea. Este é o tratamento de escolha para as fraturas agudas do antebraço distal em cães das raças miniaturas (CAMPBELL, 1980; LARSEN et al., 1999; FERRIGNO et al., 2007). No presente estudo, apesar de não ter sido utilizado nenhum tipo de imobilização externa, nem enxerto esponjoso autógeno, e somente com a fixação da placa, a consolidação das fraturas ocorreu com poucas complicações.

Quedas ou pulos foram as causas mais comuns das fraturas nos cães deste estudo. Esse tipo de trauma pode criar uma carga compressiva no eixo ósseo e resultar nos tipos de fraturas observados, além de ser 
um quadro que ocorre tipicamente em cães jovens em crescimento (MUIR, 1997; HARASEN, 2003). Os cães apresentaram-se com fraturas agudas, com histórico de trauma mínimo.

As fraturas observadas no exame radiográfico foram do tipo transversa ou oblíqua curta do antebraço. Esses padrões são similares a fraturas do tipo Cooles, que ocorrem comumente em humanos e se caracterizam por um fragmento distal de aproximadamente $0,3 \mathrm{~cm}$.

Desde a invenção dos pinos intramedulares, dos fios metálicos, das placas convencionais e de parafusos, muitas complicações têm sido observadas no tratamento de fraturas distais de rádio e ulna de cães miniaturas, como resultado da interferência desses implantes no suprimento sanguíneo do periósteo e endósteo, de um osso que é considerado pouco vascularizado. As desvantagens incluem união retardada e não união, além de quebras dos implantes (LAPPIN et al., 1983; OLMSTEAD, 1991). Neste estudo não se observou quebra dos implantes e a placa com garras não interferiu na consolidação óssea.

O uso de placas e parafusos é um método popular de fixação de fraturas do rádio e da ulna em pacientes humanos e cães (LAPPIN et al., 1983; ROCHAT \& PAYNE, 1993; WATERS et al., 1993). As dimensões das placas foram compatíveis com os rádios dos animais miniaturas e apresentaram-se resistentes à torção e fadiga do material, visto que o movimento excessivo do membro operado no pós-operatório imediato, em face da índole agitada dos animais miniaturas, poderia levar à quebra do implante. As placas aliadas às garras laterais favoreceram a redução e o alinhamento do eixo ósseo e do foco de fratura, em função do recobrimento parcial ao osso e, por possuir formato semitubular, promoveu, consequentemente, fortalecimento gradual de um osso extremamente frágil, apoio precoce do membro, num período de quatro a sete dias, em função das placas metálicas com garras, que promoveram suporte mecânico ao osso receptor, obedecendo a um dos objetivos da fixação com placas e parafusos.

O sucesso clínico da osteossíntese depende de vários fatores, incluindo a escolha do paciente, a qualidade da placa implantada, o período de implantação e a possibilidade de instalação de processos corrosivos no metal, influenciados pelo meio biológico que o cerca. A liga de titânio utilizada neste estudo apresentou boas qualidades para uso clínico, por ser de material resistente ao processo de corrosão. Além disso, o titânio é um metal mais leve que o aço inoxidável, tem certa maleabilidade, facilitando, dessa maneira, o bom assentamento da placa ao osso e a aderência do osteoblasto em sua superfície, características estas muito benéficas para o processo de consolidação (UHTHOFF, 1981; SARDINAS \& MONTAVON, 1997).

A placa utilizada no presente estudo foi desenvolvida com base nos estudos de MENNEN (1984a, 1984b), que criou uma alternativa para a manutenção da posição de fraturas em osso longo de humanos. A alternativa consistia em utilizar-se de uma placa paraesquelética em forma de $\mathrm{C}$, que possuía a vantagem de ter efeito mínimo sobre o processo de consolidação. Essa placa tinha a forma de uma ponte central com projeções laterais na forma de dedos dos dois lados, de modo a formar um semicírculo quando colocada sobre a superfície do osso com o auxílio de uma ferramenta de apertar essas projeções.

As dimensões das placas foram adequadas para favorecer a redução dos fragmentos ósseos e fixação no osso receptor. As garras abraçaram aproximadamente $50 \%$ da circunferência do rádio, e a técnica usada para aplicação da placa de titânio com garras consistiu de mínimo afastamento dos tecidos moles.

Com base nas avaliações radiográficas do pósoperatório imediato, observou-se perfeito alinhamento do foco de fratura, critério considerado primordial para que ocorram estabilidade e sucesso da consolidação óssea, conforme preconizado por SARDINAS \& MONTAVON (1997).

Nas avaliações radiográficas subsequentes observou-se consolidação óssea primária devido à estabilização do foco de fratura e não formação de calo ósseo exuberante. A linha de fratura, visível aos trinta e sessenta dias, desapareceu totalmente aos noventa dias.

As complicações observadas em dois casos resultaram da perda da função dos parafusos distais, em virtude de áreas de osteólise ao redor destes, que contribuíram para o afastamento parcial da placa do segmento distal e posterior atrito contínuo ao tecido adjacente, o que levou a sua exposição, em um caso. A rotação do fragmento distal ocorreu por deslocamento total dos parafusos distais, afastando completamente a placa do osso em outro animal. Apesar disso, ambos os 
casos tiveram evolução favorável com a consolidação das fraturas e retorno à função normal.

\section{CONCLUSÕES}

Considerando-se os resultados obtidos no presente trabalho, pode-se concluir que as fraturas de rádio e ulna de cães pertencentes a raças miniaturas e reparadas com placas semitubulares de titânio com garras tiveram sucesso na consolidação óssea e favoreceram a volta da função dos membros fraturados, sem apresentar complicações graves de consolidação óssea.

\section{REFERÊNCIAS}

ADAMIAK, Z.; ALEKSIEWICZ, R. Treatment of fractured antebrachial bones in both thoracic extremities in toy breed dogs by application of reconstruction plates. Polonian Journal Veterinary Science, n. 9, v. 3, p. 201-205, 2006.

BALFOUR, R. J.; BOUDRIEAU, R. J.; GORES, B. R. T-plate of distal radial closing wedge osteotomies for treatment of angular limb deformities in 18 dogs. Veterinary Surgery, v. 29, p. 207$217,2000$.

BRIANZA, S. Z.; DELISE, M.; FERRARIS, M. M.; D'AMELIO, P.; BOTTI, P. Cross-sectional geometrical properties of distal radius and ulna in large, médium and toy breed dogs. Journal Biomechanics, v. 39, n. 2, p. 302-311, 2006.

CAMPBELL, J. R. Healing of radial fractures in miniature dogs. Veterinary Annual, v. 20, p. 103-119, 1980.

COETZEE, G. L. Long bone fracture fixation with an intramedulary pin and c-clamp-on plate in dogs:21 cases (1992-1997). Veterinary Compendium Orthopaedics Traumatology, n. 12, p. 26-32, 1999.

FERRIGNO, C. R. E.; DELLANINA, M. I.; FANTONI, D. T. Estudo comparativo entre as osteossínteses com placas e osteossínteses com placas associadas a enxertos de proteína morfogenética óssea (Gen-Tech $\left.{ }^{\circledR}\right)$ em fraturas distais de rádio-ulna em cães com menos de 6 quilos. Pesquisa Veterinária Brasileira, v. 37, n. 2, 2007. HAAS, N.; HAUKE, C.; SCHÜTZ, M.; KÄÄB, M.; PERREN, S. $M$. Treatment of diaphyseal fractures of the forearm using the point contact fixator (PC-fix): Results of 387 fractures of a prospective multicentric study (PC-fix II). Injury, v. 32, p. 51-62, 2001.

HAMILTON, M. H.; LANGLEY HOBBS, S. J. Use of the AO veterinary mini ' $\mathrm{T}$ '-plate for stabilization of distal radius and ulna fractures in toy breed dogs. Veterinary Compendium Orthopedics Traumatology, v. 18, n. 2, p. 114, 2005.
HARARI, J.; SEGUIN, B.; PADGETT, S. L. Principles of external skeletal fixation in small animal surgery. Veterinary Medicine, $v$. 9, n. 5, p. 445-453, 1998.

HARASEN, G. Common long bone fracture in small animal practice - Part 2. Canine Veterinary Journal, v. 44, p. 503-504.

LAPPIN, M. R.; ARON, D. N; HERRON, H. L. Fractures of the radius and ulna in the dog. Journal of the American Animal Hospital Association, v. 19, n. 9, p. 643-650, 1983.

LARSEN, L. J.; ROUSH, J. K.; McLAUGHLIN, R. M. Bone plate fixation of distal radius and ulna fractures in small-and miniature-breed dogs. Journal of the American Animal Hospital Association, Lakewood, v. 35, p. 243-250, 1999.

MENNEN, U. The paraskeletal clamp-on plate. Part I. A new alternative for retaining the surgically reduced position of bone fractures. South African Medical Journal, v. 66, n. 4, p. 167170, 1984a.

MENNEN, U. The paraskeletal clamp-on plate. Part II. Clinical experience with fractures of the radius and/or ulna South African Medical Journal, v. 66, n. 4, p. 170-172, 1984 b.

MUIR, P. Distal antebrachial fractures in toy-breed dogs. Compendium on Continuing Education for the Practicing Veterinarian, v. 19, n 2, p. 137-145, 1997.

OLMSTEAD, M. L. Complications of fractures repaired with plates and screw. Veterinary Clinics of North America Small Animal Practice, v. 21, n. 4, p. 669-686, 1991.

RAHAL, S. C.; VOLPI, R. S.; KHADIJE, H.; VULCANO, L. C.; BÜTNER, R. C. Emprego de fixador externo circular no tratamento de complicações de fraturas do rádio e ulna em cães de raças pequenas. Ciência Rural, v. 35, n. 5, 2005.

ROCHAT, M. C.; PAYNE, J. T. Your options in managing longbone fractures in dogs and cats. Veterinary Medicine, v. 88, n. 10, p. 946-956, 1993.

RUDD, R. G.; WHITEHAIR, J. G. Fractures of the radius and ulna. Veterinary Clinics of North America, v. 22, n. 1, p. 135-148, 1992.

SAIKKU-BÄCKSTRÖM, A.; RÄIHÄ, J. E.; VÄLIMAA. T.; TULAMO, R. M. Repair of radial fractures in toy breed dogs with self-reinforced biodegradable bone plates, metal screws, and light-weight external coaptation. Veterinary Surgery, v. 34, n. 1, p. 11-17, 2005.

SARDINAS, J. C.; MONTAVON, P. M. Use of medial boné plate for repair of radius and ulna fractures in dogs and cats: a report of 22 cases. Veterinary Surgery, v. 26, n. 2, p. 108-113, 1997. 
UHTHOFF, H. K.; BARDOS, D. I.; LISKOVA-KIAR, M. The advantages of titanium alloy over stainless steel plates for the internal fixation of fractures an experimental study in dogs. The Journal of Bone and Joint Surgery, v. 63 B, n. 3, p. 427-434, 1981.

WATERS, D. J.; BREUR, G. J.; TOOMBS, J. P. Treatment of common forelimb fractures in miniature-and toy-breed dogs.
Journal of the American Animal Hospital Association, v. 29, n. 9 , p. $442-448,1993$.

WELCH, J. A.; BOUDRIEAU, R. J.; DeJARDIM, 1. M.; SPONDINICK, G. J. The intraosseous blood supply of the canine radius: implications for healing of distal fractures in small dogs. Veterinary Surgery, v. 26, n. 1, p. 57-61, 1997.

Protocolado em: 5 dez. 2007. Aceito em: 17 mar. 2010. 